\author{
UNIVERSIDADE DE BRASÍLIA \\ FACULDADE DE MEDICINA \\ NÚCLEO DE MEDICINA TROPICAL \\ CURSO DE ESPECIALIZAÇÃO EM MEDICINA TROPICAL
}

Margarita Maria Ochoa Diaz

\title{
PROCALCITONINA COMO BIOMARCADOR DIAGNÓSTICO NAS DOENÇAS INFECCIOSAS
}

Brasília

2008 
UNIVERSIDADE DE BRASÍLIA

FACULDADE DE MEDICINA

NÚCLEO DE MEDICINA TROPICAL

CURSO DE ESPECIALIZAÇÃO EM MEDICINA TROPICAL

\author{
Margarita Maria Ochoa Diaz
}

\title{
PROCALCITONINA COMO BIOMARCADOR DIAGNÓSTICO NAS DOENÇAS INFECCIOSAS
}

\begin{abstract}
Monografia apresentada como parte da avaliação final do Curso de Especialização em Medicina Tropical pelo Núcleo de Medicina Tropical da Universidade de Brasília.
\end{abstract}

Orientador: Prof. Celeste Aída Nogueira Silveira 
Dedico este trabalho a minha família e a Deus, pois são eles quem deram sentido a minha vida 


\section{AGRADECIMENTOS}

Agradeço a Deus, pois foi Ele quem me motivou para voltar de novo às aulas, para continuar nesta tarefa que me confiou para levar conforto ao corpo e alma de meus

pacientes.

Agradeço a meus pais e minha irmã representação física do amor de Deus e pilares fundamentais para seguir lutando cada dia por o bem-estar não só meu, se não deles, daí o sentido da minha vida.

Aos professores que não se conformaram com transmitir conhecimento, se não que foram maestros que semearam a duvida de fortalecer minhas capacidades de assombro para hoje quer cada dia mais respostas a meus interrogantes e perguntas que solucionem minhas hipóteses.

Finalmente, e não menos importante, agradeço a meus pacientes por ser eles quem estimularam em mim o desejo para ser um melhor ser humano digno para seu serviço. 
"A maturidade começa a manifestasse quando sentimos que nossa preocupação é maior por os demais que por nós mesmos"

Albert Einstein, (1879-1955) 
SUMARIO

LISTA DE ABREVIATURAS

RESUMO

ABSTRACT 


\section{LISTA DE ABREVIATURAS}

AB

ACCP

APACHE

$\mathrm{COLD}=\mathrm{DPOC}$

CT

IL

LIA

LRTI

PAC

PAN

PCR

PCT

PSI

SCCM

SDMO

SIRS

SOFA
Antibiótico

American College of Chest Physicians

Acute Physiology and Chronic Health Evaluation

Doença Pulmonar Obstrutiva Crônica

Chronic Obstructive Lung Disease

Calcitonina

Interleucina

Ensaio imuno-luminométrico

Luminometric Immuno Assay

Infecção Trato Respiratório Inferior

Lower Respiratory Tract Infection

Pneumonia Adquirida na Comunidade

Peptídeo Atrial Natriurético

Proteína C Reativa

Procalcitonina

Pneumonia Severidade Índice

Society of Critical Care Medicine

Síndrome da Disfunção de Múltiplos Órgãos

Síndrome da Resposta Inflamatória Sistêmica

Sepsis-related Organ Failure Assessment 
TNF Fator de Necrose Tumoral

UTI Unidade de Terapia Intensiva

VAP Pneumonia Associada ao Ventilador

VHS Velocidade de hemossedimentação 


\section{RESUMO}

Sepse é um dos desfechos mais temidos hoje em nossa prática clínica sendo responsável por mais do $30 \%$ dos óbitos do mundo. Por tal motivo, a cada dia se tem maior interesse em conhecer e estudar marcadores séricos que permitam antecipar o desenlace de um evento infeccioso.

Os Biomarcadores são ferramentas promissoras no campo da saúde, podem agilizar no diagnóstico clínico da presença da infecção bacteriana, severidade delas e resposta ao tratamento.

Procalcitonina (PCT), precursor da calcitonina produzida no maior grau nas células C neuroendócrinas da glândula tireóide, incrementa seus níveis nos processos infecciosos bacterianos "generalizados", atribuídos a uma origem extratiroideo desta, tendo ao sistema reticuloendotelial e ao tecido parenquimatoso como suas principais fontes.

Em paciente com sepse, níveis de PCT podem aumentar até 5000-10000 vezes com níveis de Calcitonina normal, podendo ser medida duas horas antes da bacteremia, pois seus níveis aumentam rapidamente.

A determinação da PCT é uma prova fácil de realizar, existem provas quantitativas mais exatas e semiquantitativas com resultados em menos de uma hora, podendo ter importância no diagnostico da sepse em pacientes com SIRS de etiologia duvidosa em UTIs.

Por isso hoje se confirma á PCT como marcador para infecções severas e sepse. Baseados na evidência proveniente de estudos de intervenção se concluiu que procalcitonina incrementasse o poder de decisão clínica e uso de antibiótico sem nenhuma repercussão nos desfechos ou efeitos adversos relacionados com ao uso de antimicrobianos. 


\section{ABSTRACT}

Today sepsis is an adverse outcome in our clinical practice, being responsible for more than $30 \%$ of deaths around the world. Therefore an interest of recognizing and investigate the biomarkers should let us to anticipate the outcome of an infection event, like sepsis.

Biomarkers are promising tools on health field, improving diagnostic of bacterial infection, severity and response of treatment.

Procalcitonin, propeptide of calcitonin produced on neuroendocrine $\mathrm{C}$ cells on thyroid gland is increased on bacterial infections because a major stimulus extra thyroid, with reticuloendothelial cells system and parenchymatous as principal sources.

On sepsis patients, leves of PCT can increase over 5000-10000 times with normal levels of calcitonin, being measurable like 2 hour before bacteremia.

Determination of PCT is easy to measure, having quantitative and semi quantitative tests, more reliable with results in like 1 hour being important on diagnosis of sepsis in patients having SIRS with unknown etiology in ICUs.

Therefore today recently studies confirm PCT as biomarker for severe infections and sepsis, based on evidence coming from interventional studies founding that procalcitonin increase clinical and antibiotic decision without repercussion on outcomes or sides effects related to antibiotic use. 


\section{1- INTRODUÇÃO}

Cada dia em nossa prática clínica enfrentamos uma variedade de patologias que devem ser solucionadas de um modo rápido e efetivo, o que representa um verdadeiro desafio para o especialista.

É por isto que esforçamos para encontrar técnicas diagnósticas que permitam estabelecer com certo grau de segurança o estado atual do paciente, e o mais importante, estabelecer o prognóstico de sua condição clínica que permita de algum modo prevenir qualquer desenlace fatal.

A sepse severa definida como disfunção orgânica aguda secundária a uma infecção, e o choque séptico que é sepse severa com hipotensão irreversível a infusão de fluído, são hoje os maiores problemas na área de saúde. Afeta milhões de indivíduos por ano em todo mundo, mata um de cada quatro pessoas acometidas, com uma tendência a aumentar cada vez mais (SCHUETZ, 2007).

O Consenso Brasileiro de Sepse aponta a síndrome de disfunção orgânica múltipla (SDMO) como a principal causa de morte de pacientes internados em unidades de terapia intensiva (UTI). A estimativa de sua prevalência varia dependendo da população estudada e dos critérios utilizados para definir a síndrome.

Nos Estados Unidos, a prevalência da SDMO é de 15\% levando-se em conta todas as admissões na UTI, e é responsável por até $80 \%$ das mortes dentro da UTI, e representa um custo de mais de 100.000 dólares por paciente ou 500.000 dólares por sobrevivente.

As ferramentas atuais que possuímos são úteis mais não ideais. Por isto, o objetivo deste trabalho é apresentar novas ferramentas com adequada aplicabilidade clínica que auxilie de 
de algum modo à definição de infecção e que nos permitam ganhar tempo, nosso principal inimigo quando os pacientes padecem de processos infecciosos.

Com a intenção de melhorar o prognóstico de tão devastadora doença com a sepse, várias técnicas laboratoriais têm sido pesquisadas e propostas com o objetivo do diagnóstico precoce. Algumas novas alternativas - os biomarcadores - têm se mostrado promissoras.

Os biomarcadores foram propostos como ferramentas adicionais para otimizar e agilizar o diagnóstico clínico. São ferramentas mais confiáveis na determinação da presença de infecções bacterianas relevantes, na severidade das mesmas e na resposta esperada do tratamento antibiótico.

Uma minuciosa história clínica constitui ainda hoje um pilar para o diagnóstico das doenças, porém durante a evolução do tratamento das infecções as decisões clínicas seriam mais efetivas se baseássemos em marcadores biológicos confiáveis e acessíveis na prática diária.

Os biomarcadores são elementos laboratoriais cada vez mais específicos, resultado de um estudo detalhado da fisiopatologia da infecção e são fatores determinantes que causam um grande avanço no dia a dia de nossos hospitais.

Esta área do conhecimento que está em franco desenvolvimento vai ajudar a mudar a conduta que até então baseada nos dados clínicos constituía um grande desafio no manejo dos doentes sépticos. 


\section{2- CONCEITOS GERIAS SOBRE SEPSE}

A "Society of Critical Care Medicine" (SCCM) e o "American College of Chest Physicians" (ACCP) adotam as seguintes definiç̧̃̃es:

1. "SIRS" (Síndrome da Resposta Inflamatória Sistêmica): é uma reação inflamatória sistêmica do organismo em resposta a agressões, infecciosa ou não, manifestada por duas ou mais das seguintes condições:

- Temperatura $>38^{\circ} \mathrm{C}$ ou $<36^{\circ} \mathrm{C}$

- Freqüência cardíaca > 90 batimentos/min

- Freqüência respiratória > 20 incursões resp/min ou PaCO2 <32 mmHg $(<4,3$ $\mathrm{kPa})$

- Leucócitos > 12.000 células $/ \mathrm{mm} 3$, ou $<4.000$ células $/ \mathrm{mm} 3$ ou $>10 \%$ de formas jovens (bastonetes).

2. SEPSE: é o SIRS na presença de foco infeccioso

3. SEPSE GRAVE: sepse com disfunção orgânica, mais:

Sinais de hipoperfusão:

- Acidose

- Oligúria

- Alteração aguda do estado mental

Hipotensão: PA sistólica $<90 \mathrm{mmHg}$ ou redução de $>40 \mathrm{mmHg}$ da linha de base, na ausência de outras causas. 
4. CHOQUE SÉPTICO: sepse grave com hipotensão, a despeito de adequada reposição de fluidos, associada à presença de anormalidades da perfusão necessitando de agentes vasopressores.

5. SDMO (Síndrome da Disfunção de Múltiplos Órgãos): disfunção orgânica em que a homeostasia não pode ser mantida sem intervenção. (BONE 1992; DELLINGER,2007; SILVA, 2003)

Na SDMO os órgãos habitualmente envolvidos são pulmões, rins, coração (incluindo o sistema vascular) e fígado. Coagulopatia, a depender da definição, parece ser o denominador comum de todo o processo microvascular que embasa fisiopatologicamente a SDMO. Outro órgão comumente envolvido é o sistema nervoso central, designado como encefalopatia séptica. No entanto, sua real prevalência é desconhecida, uma vez que pacientes sépticos se encontram, muitas vezes, sedados (SILVA, 2003). 


\section{3 - EPIDEMIOLOGIA DA SEPSE}

\subsection{Dados Epidemiológicos Norte-Americanos}

Dados recentes sobre incidência de sepse nos Estados Unidos são oriundos de um novo relatório do CDC (ANDERSON, 2002) e de um grande estudo epidemiológico conduzido por Angus et al. (ANGUS, 2001).

O relatório do CDC referente ao ano 2000, mesmo utilizando o termo septicemia, referiu "sepse" como a $10^{\mathrm{a}}$ causa de morte, sendo responsável por 1,3\% das mortes naquele ano (Tab. 1) No estudo de Angus, os autores estimaram em 750.000 novos os casos, a cada ano, com taxa de mortalidade entre 35 e $50 \%$, o que representaria 200 a 300.000 mortes por sepse grave e choque séptico. $\mathrm{O}$ estudo de Angus foi baseado em análise retrospectiva de 6.621 .559 admissões hospitalares em sete estados americanos (aproximadamente $25 \%$ da população). Nessa amostra populacional, os autores identificaram 192.980 casos de sepse grave durante o ano 1995. Após ajustes para idade e sexo, poder-se-ia afirmar que a incidência anual de sepse grave naquele país é de 3,0 casos por 1000 habitantes ou 2,6 casos por 100 altas hospitalares. Vale ressaltar que essa incidência engloba adultos e crianças. Talvez esse seja o único estudo epidemiológico em sepse com essa característica. Outro dado interessante desse estudo é que perto dos $55 \%$ dos pacientes com sepse grave apresentavam alguma co-morbidade. Metade dos pacientes com sepse grave identificados recebeu, em algum momento de sua hospitalização, cuidados intensivos. A taxa de mortalidade global foi de $28,6 \%$ e apresentava relação quase linear com a idade ( $10 \%$ em crianças e $38,4 \%$ nos adultos $\geq 85$ anos). Os autores destacaram ainda os custos relacionados ao paciente com sepse grave. Cerca de 22.000 dólares eram gastos por paciente, sendo que os não sobreviventes despendiam maiores recursos, em torno de 26.000 dólares. Pacientes internados em terapia intensiva alcançavam cifras superiores, cerca de 30.000 dólares. Assumindo um crescimento anual de $1.5 \%$ casos 
1,5\% casos por ano, chegaríamos naquele país a 934.000 novos casos em 2010 e de 1.110 .000 casos no ano de 2020. (SILVA, 2003).

\begin{tabular}{|c|c|c|c|c|c|}
\hline \multirow[b]{2}{*}{ Cause of death and year } & \multirow[b]{2}{*}{ Rank' } & \multicolumn{2}{|c|}{2000} & \multicolumn{2}{|c|}{1999} \\
\hline & & Deaths & $\begin{array}{l}\text { Percent of } \\
\text { total deaths }\end{array}$ & Deaths & $\begin{array}{l}\text { Percent of } \\
\text { total deaths }\end{array}$ \\
\hline All causes $\ldots \ldots \ldots \ldots \ldots \ldots \ldots \ldots \ldots \ldots \ldots \ldots \ldots$ & $\ldots$ & $2,403,351$ & 100.0 & $2,391,399$ & 1000 \\
\hline Diseases of heart . . . . . . . . . . . . . . . . . . . . . (100-109, $111,113,120-151)$ & 1 & 710,760 & 29.6 & 725,192 & 30.3 \\
\hline Malignant neoplasms . . . . . . . . . . . . . . . . . . . . . . . . . . . . (COD-C97) & 2 & 563,091 & 23.0 & 549,838 & 23.0 \\
\hline Cerebrovascular diseases . . . . . . . . . . . . . . . . . . . . . . . (160-169) & 3 & 167,661 & 7.0 & 167,366 & 7.0 \\
\hline Chronic lower respiratory diseases. . . . . . . . . . . . . . . . . . . . . . . . (J40-J47) & 4 & 122,009 & 5.1 & 124,181 & 5.2 \\
\hline Accidents (unintentional injuries) . . . . . . . . . . . . . . (V01-Y59, Y85-Y86) & 5 & 97,900 & 4.1 & 97,860 & 4.1 \\
\hline 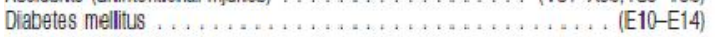 & 6 & 69,301 & 2.9 & 68,399 & 2.9 \\
\hline 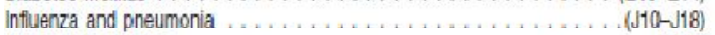 & 7 & 65,313 & 27 & 63,730 & 2.7 \\
\hline Alzheimer's disease. . ........ . . . . . . . . . . . . . . . . . (G30) & 8 & 49,558 & 2.1 & 44,536 & 1.9 \\
\hline Nephritis, nephrotic syndrome and nephrosis. . . . . (NO0-N07,N17-N19,N25-N27) & 9 & 37,251 & 1.5 & 35,525 & 1.5 \\
\hline 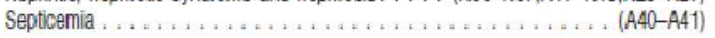 & 10 & 31,224 & 1.3 & 30,680 & 1.3 \\
\hline
\end{tabular}

Category not appicable.

'Hank based on number of deaths.

TABELA 1 - Óbitos e porcentagem de mortes totais das dez principais causas de morte: USA, 1999-2000.

Fonte: ANDERSON, 2002

\subsection{Dados Epidemiológicos Europeus}

Recentemente, Alberti e colaboradores (2002) publicaram um elegante e completo estudo epidemiológico englobando 28 unidades de terapia intensiva da Europa. Os autores avaliaram, em um ano de acompanhamento, 14.364 pacientes admitidos nessas UTIs. As definições utilizadas nesse estudo estavam de acordo com a reunião de consenso das Sociedades Americanas do Tórax e de Terapia Intensiva. Os pacientes foram avaliados diariamente durante todo um período de internação. Do número total de pacientes avaliados, 6.011 permaneceram menos de 24 horas na UTI e não foram avaliados plenamente ao longo do estudo. O principal achado desse estudo foi que a incidência de infecção foi de $21,1 \%$, e nos pacientes que permaneceram na UTI por mais de 24 horas, a incidência foi de 18,9\%, incluindo $45 \%$ dos pacientes infectados já na admissão na UTI. Novecentos e quarenta e quatro pacientes preencheram os critérios de sepse grave (6,6\% do total de pacientes), enquanto que 1.180 pacientes preencheram os critérios de choque séptico ( $8,2 \%$ do total de 
pacientes). A taxa de mortalidade hospitalar variou de $16,9 \%$ nos pacientes não-infectados a 53,6\% naqueles com infecção adquirida no hospital. A taxa de mortalidade hospitalar dos pacientes com sepse ficou entre 44,8 e 67,9 (IC 95\%) e dos pacientes com choque séptico entre 47,2 e 63,8\% (IC 95\%). (SILVA, 2003).

\subsection{Dados Epidemiológicos Latino-Americanos}

O estudo BASES (Brazilian Sepsis Epidemiological Study) (SILVA, 2004) vem sendo desenvolvido no Brasil desde maio de 2002. Inicialmente cinco diferentes unidades de terapia intensiva de 2 regiões (sul e sudeste) do Brasil foram incluídas.

Trata-se de um estudo prospectivo, de coortes, que avalia todos os pacientes admitidos nessas unidades, independentemente de sua patologia. Diariamente e durante todo o período de internação na UTI, os investigadores catalogam dados clínicos e laboratoriais no sentido de verificar a presença de SIRS, sepse, sepse grave e choque séptico. Dois grupos acabam sendo prospectivamente formados: a) pacientes que permanecem menos de 24 horas na UTI e b) aqueles que permanecem mais de 24 horas.

Nos pacientes com mais de 24 horas, a incidência de sepse grave e de choque séptico foi de $27 \%$ e $23 \%$, respectivamente. Em geral, a morte do paciente séptico teve maior relação com o evento infeccioso do que com a doença de base, quando essa ocorre no período hospitalar. (SILVA, 2003).

Do acordo com Silva e colaboradores para os 1383 pacientes a incidência do sepse foi 57.9 (95\% CI 51.5-65.3) por 1000 paciente-dia ou 421 eventos do sepse, que corresponde ao 30.5 (28.9-32.1) das admissões nas UTIs.

A mortalidade do pacientes com SIRS, sepse, sepse severa e choque séptico foi $24,2 \%$, $33.9 \%, 46.9 \%$ e $52.2 \%$ respectivamente (Figura 1). Para pacientes com SIRS sim infecção a mortalidades foi 11.3\% (SILVA, 2004). 


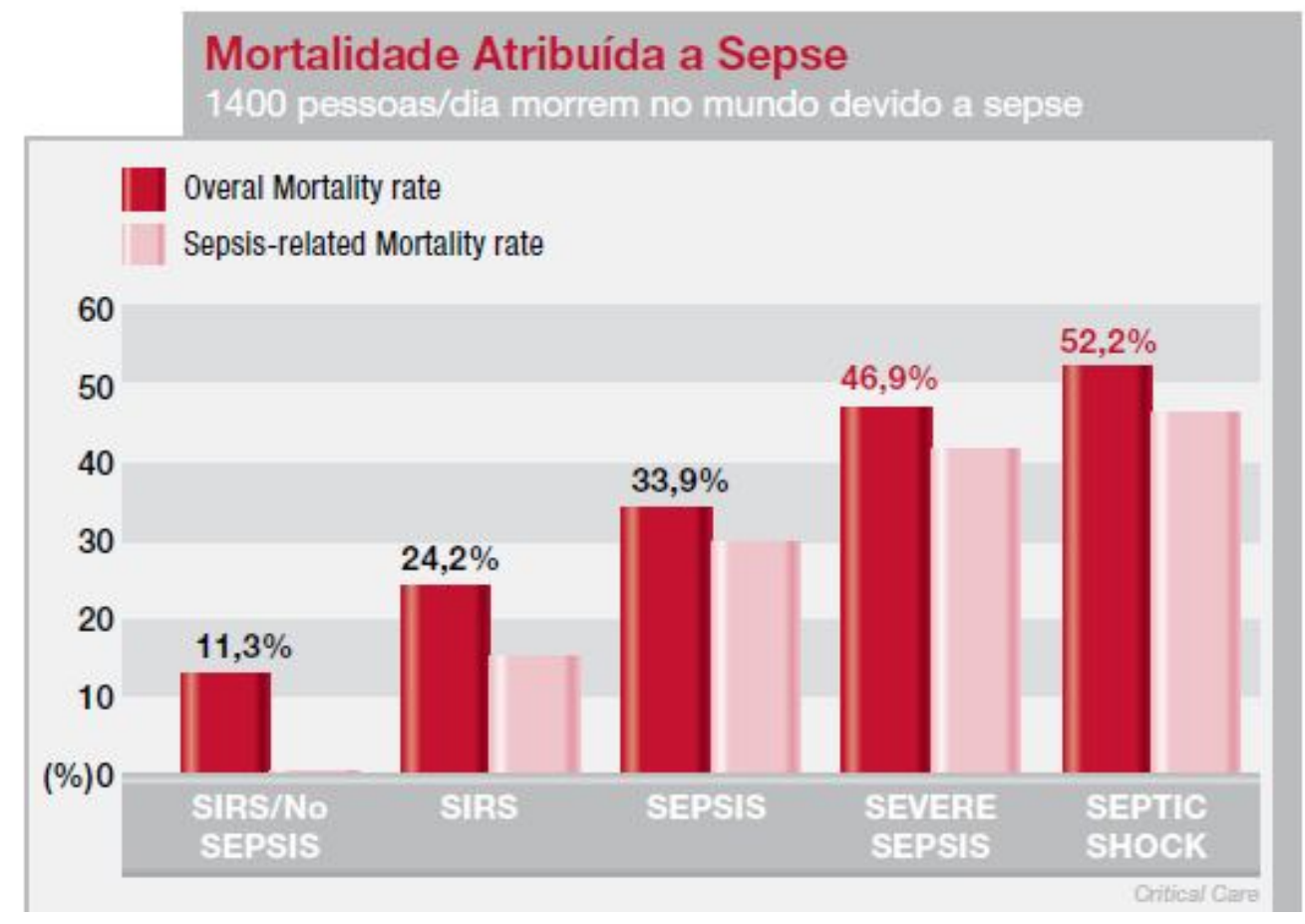

Figura 1: Mortalidade atribuída à sepse.

Fonte: SILVA, 2004 


\section{4 - ASPECTOS GERAIS SOBRE BIOMARCADORES:}

Atualmente possuímos parâmetros clínicos, hemodinâmicos e laboratoriais convencionais para tentar diagnosticar os sinais do SIRS mais isso não explica completamente os diversos desfechos pela sepse.

O diagnóstico precoce e a determinação da resposta inflamatória pelo organismo à infecção é crucial para o manejo e desenlace destes pacientes, mas esta tarefa é com os marcadores rotineiros (febre, leucocitose, proteína-C reativa $[\mathrm{PCR}]$ ). Ainda que a hemocultura seja o melhor método para diagnóstico da infecção, isto não indica bem a resposta do hospedeiro, nem diferença entre colonização e complicações sistêmicas, como resposta inflamatória sistêmica pela infecção, ou infecções bacterianas invasivas (UZZAN, 2006).

Além dos parâmetros clínicos, hemodinâmicos e laboratoriais convencionais, diversos estudos têm demonstrado ser possível caracterizar a SRIS (infecciosa ou não) através da presença ou ausência de determinados marcadores biológicos associados ao processo inflamatório e infeccioso. Na verdade, uma característica marcante e invariável da SRIS é a indução e liberação de diversas citocinas e proteínas de fase aguda, tanto pró quanto anti-inflamatórias, cujos níveis séricos se elevam rapidamente durante a resposta inflamatória. Vários estudos têm documentado que as principais citosinas (TNF-alfa, IL-1, IL-6, IL-8, IL-10, IL-12 e IL18) e alguns de seus receptores solúveis (por exemplo, receptor TNF-R55) estão consistentemente aumentados tanto no sepse como na SRIS de origem não-infecciosa. Tais evidências, no entanto, ajudam um pouco a caracterizar a resposta inflamatória sistêmica em geral, mas não ajudam muito a elucidar a presença (ou ausência) da infecção como desencadeante da síndrome, o que seria altamente desejável, sendo pouco específicas para o diagnóstico da sepse (SRIS de origem infecciosa). Por outro lado, a determinação dos níveis 
séricos das citocinas não parece ser um método muito útil para o dia-a-dia da prática clínica (SILVA 2003).

Biomarcadores foram propostos como ferramentas diagnósticas para aperfeiçoar e agilizar o diagnóstico clínico na determinação da presença da infecção bacteriana relevante, severidade dela, e resposta ao tratamento. (SCHUETZ, 2007).

Os requerimentos para um marcador de sepse ideal são altos graus de sensibilidade $e$ especificidade, facilidades de manejo e baixo custo. $\mathrm{O}$ marcador deve indicar os estadios da doença e o prognóstico desta. O biomarcador é útil só se este adiciona valor ao critério médico e deve reunir as seguintes condições:

1. Reduzir o tempo para acrescentar o diagnóstico.

2. Facilitar a diferenciação entre causas infecciosas e não infecciosas da inflamação e suas seqüelas, disfunção orgânica ou choque.

3. Permitir a diferenciação entre infecção viral e bacteriana.

4. Refletir a efetividade do tratamento antimicrobiano, sendo mais exato que os sinais clínicas e laboratoriais. (REINHART, 2006)

Além do mais, três alvos terapêuticos são planejados para os biomarcadores:

1. Capacidades antimicrobianas das hormocinas, especialmente a Adrenomedulina, podem ser usadas para o desenvolvimento dos antibióticos.

2. Seguindo o principio da "sola dosis facit venenum", a concentração dos biomarcadores produzidos endógenamente, pudesse retornar tóxica ao organismo. Por exemplo, a administração de procalcitonina no hamsters com peritonite, pode dobrar a taxa de mortalidade. De modo oposto, o tratamento com procalcitonina-reativa antisórica incrementa a sobrevida de hámsters sépticos e porcos com sepse mono e polimicrobiana respectivamente, destacando seu papel significativo na sepse (NYLEN, 1998). 


\subsection{Resposta Humoral e celular do hospedeiro}

Os biomarcadores na sepse são derivados de uma resposta complexa do hospedeiro ao estímulo infeccioso, isto é, toxinas bacterianas, ou antígenos da superfície da membrana (padrão molecular associado à patógenos), que podem iniciar a ativação das vias plasmáticas (sistema do complemento, cascata da coagulação, sistema calicreina-cinina, eicosanóides) e celulares (granulocitos, trombocitos, macrófagos, células endoteliais) liberando diferentes mediadores e moléculas (citocinas, quimiocinas, proteínas do fase aguda) (REINHART, 2006).

Procalcitonina, Proteína C-reactiva e Interleucina-8, podem melhorar a avaliação diagnóstica das infecções e guiar a terapia antibiótica.

Biomarcadores de prognóstico incluem: Cortisol, Proadrenomedulin, Copeptin, e Peptídeos Natriuréticos.

A severidade de uma doença representa um consumo de maiores recursos na área de saúde, incluindo a necessidade de hospitalização, UTIs, eleição ou não dos agentes antimicrobianos, entre outros.

Atualmente há complexos sistemas de classificação como o APACHE II e PSI. O primeiro não foi desenhado para ser usado na predição dos desfechos individuais, entanto o PSI é muito complexo, comprometendo sua disseminação e implementação especialmente na prática diária.

$\mathrm{Na}$ atualidade, as proteínas da fase aguda, hormonais e lipoproteínas, podem repercutir no prognóstico. Diferente do PCR e da contagem de leucócitos, a dinâmica dos níveis do procalcitonina tem implicações prognósticas, como que níveis persistentemente elevados se associam a desfechos adversos. (Tab. 2) 
De modo oposto, a diminuição dos níveis do procalcitonina sugere um desfecho favorável, usualmente mostrando a queda em um log. e uma vida média após 20-24hr (BECKER, 2004).

Adrenomedulina é outra hormocina da família do gene CALC e é um dos agentes vasodilatadores mais potentes com propriedades bactericidas e inmuno-moduladoras.

Os níveis da proadrenomedulina estão elevados na sepse e no PAC, tendo uma precisão similar como preditor do óbito comparado com o APACHE II, e melhora a exatidão do prognostico do PSI somente na PAC, oferecendo uma margem adicional de segurança.

Peptido Atrial Natriurético (PAN), um membro da família dos Peptídeos Natriuréticos, regula uma variedade de parâmetros fisiológicos. Devido a sua longa vida media, a porção Nterminal de proPAN particularmente a região media desta molécula (MR-proPAN) mostrou ser a mais confiável para analisar.

Na NAC, o nível da pro-PAN pode refletir a resposta inflamatória das citocinas correlacionando a severidade da Pneumonia, e também a presença de comorbilidades relevantes, como a falha cardíaca e renal. (SCHUETZ, 2007)

Um estudo realizado em Basel (Suíça), níveis plasmáticos de MR-proPAN se incrementaram no pacientes com LRTI, com valores superiores em NAC comparado com medições clínicas mais comuns e parâmetros de laboratório incluindo PSI.

Numa coorte de pacientes com dispnéia predominando falha cardíaca congestiva foi testado o peptídeo natriurético tipo B sendo útil para a estratificação do risco no subgrupo do pacientes com PAC (MÜLLER, 2005).

A Vasopressina tem efeito osmoregulador assim como hemodinâmico e reflete a resposta individual ao estresse. A Copeptina e sintetizada com a Vasopressina, refletindo de modo direto nos níveis da vasopressina, mas a copeptina é mais estável no plasma e soro. Fora 
encontrados níveis da copeptina maiores em pacientes com LRTIs comparado com controles $(\mathrm{p}<0.001)$ com níveis maiores na PAC.

O nível da copeptina aumenta com a severidade da PAC, isso mesmo, fazendo o PSI. De maneira semelhante, a copeptina mostrou ser predictora da falha clínica de longo prazo no paciente com exacerbações agudas do EPOC, independentemente da idade, comorbidade, hipoxemia e incapacidade funcional pulmonar. (SCHUETZ, 2007)

Por isto é recomendável basear a difícil decisão de estimar o prognóstico e tratamento em vários parâmetros e não em um só, cada um deles refletindo aspectos fisiopatológicos diferentes.

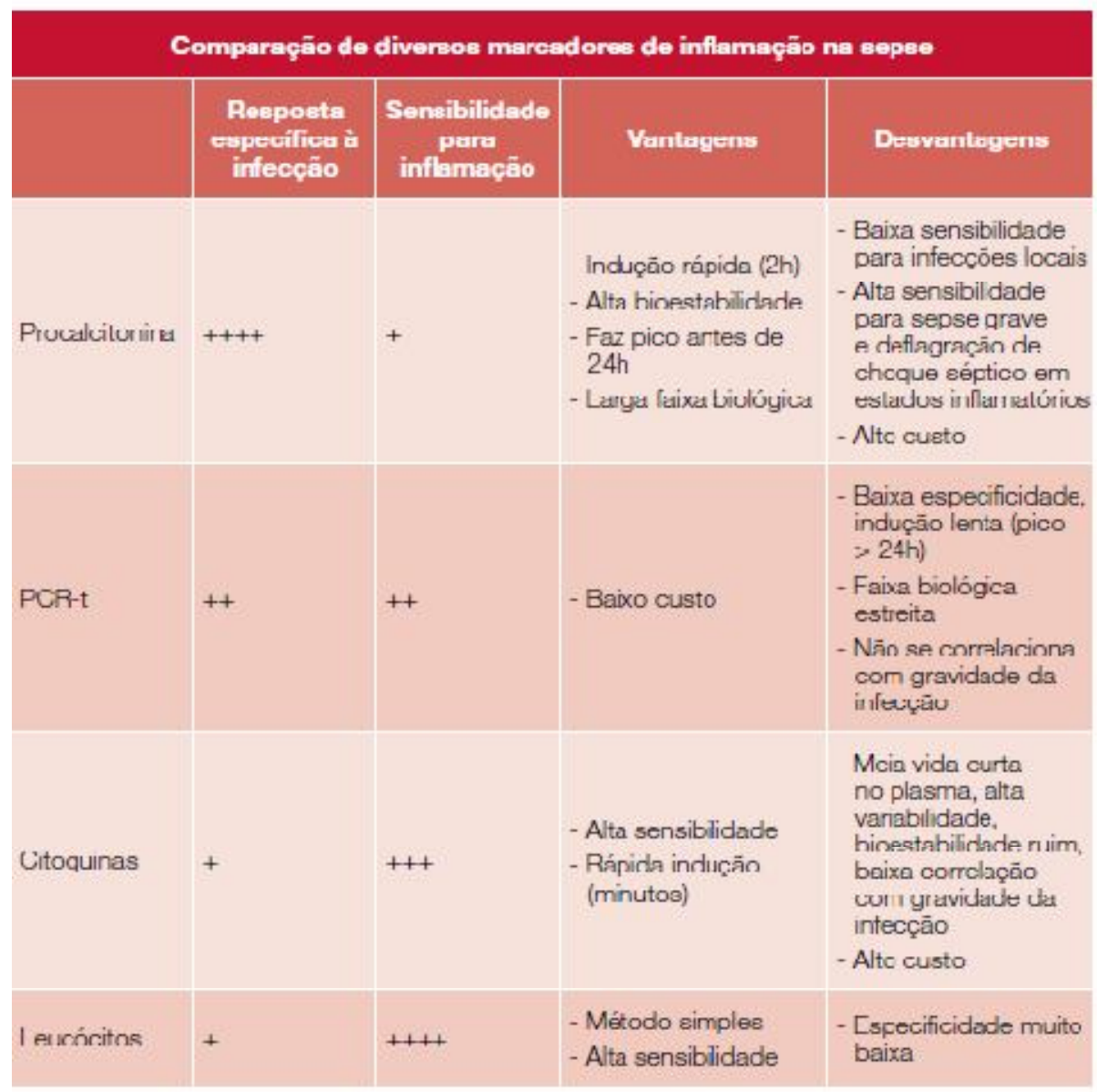

Tabela 2: Comparação de Diversos Marcadores de Inflamação na Sepse. Fonte: KONRAD, 2006. 


\section{5- VANTAGENS E DESVANTAGENS DOS BIOMARCADORES}

- Os biomarcadores não podem determinar o agente causal e padrão de associação da susceptibilidade antibiótica. Por tanto, não é possível detectar o agente causal da febre no $60-80 \%$ dos pacientes suspeitos de infecção sanguínea (Bloodstream infection) primária ou secundaria.

- Diferentes microorganismos podem induzir distintas respostas em vários órgãos dando como resultado um amplo repertório do Biomarcadores circulantes e mediadores, mas nenhuma infecção é tão complexa como para ser simplificada a um só biomarcador.

- Os signos clínicos de infecção e provas laboratoriais (e.g. contagem células brancas, VHS, PCR) carecem de exatidão diagnóstica e podem ser enganosos.

- Diferençar uma verdadeira infecção da contaminação depois do crescimento de comensais cutâneos habituais em hemoculturas o de comensais respiratórios no escarro do pacientes com Doença Pulmonar Obstrutiva Crônica (DPOC) faz que o diagnóstico seja até mais complicado.

- O valor adicional dos biomarcadores no cuidadoso critério clinico das LRTIs está bem descrito no grande estudo multicêntrico ProHOSP (SCHUETZ,2007) 


\section{6 - PROCALCITONINA COMO BIOMARCADOR EM SEPSIS}

\subsection{Fisiopatologia}

A Procalcitonina (PCT) é o pro-peptídeo da calcitonina de 13-kd.(REINHART 2006). O precursor da PCT e calcitonina o qual é expresso no gene da calcitonina I (CALC I) que se encontra no cromossomo 11. A produção endócrina da calcitonina (hormônio maduro) é produzida em maior grau nas células $C$ neuroendócrinas da glândula tireóide. Sabemos que normalmente a transcrição extra-tireóide do gene CALC-I é supressa e sua expressão é limitada seletivamente nas células neuroendócrinas encontradas principalmente na glândula tireóide e no pulmão (produção hormonal normal de PCT e calcitonina). Nestas células neuroendócrinas o hormônio maduro é processado e depositado nos grânulos secretórios no citoplasma.

Ao se produzir um estímulo bacteriano, os tecidos parenquimatosos não depositam a PCT e calcitonina nos grânulos secretórios do citoplasma devido a que as bactérias induzem a sobreregulação do gene CALC-I provocando o inicio da síntese e liberação dos precursores da calcitonina (PCT principalmente) em todos os tecidos parenquimatosos, transformando-se este tecido em uma glândula produtora de esses pro - hormônios e hormônios (PCT; calcitonina).

Existem outros mecanismos que provocam sobre-regulação do gene CALC-I, como são IL-1, FNT- $\alpha$ ao diminuir a proteólise da PCT a calcitonina, logrando que quantidades desta (PCT) sejam liberadas à circulação sistêmica. Por isso nos processos infecciosos bacterianos "generalizados" o incremento nos níveis da PCT é atribuído a uma origem extra-tireoideo, sendo o sistema reticuloendotelial e tecido parenquimatoso como as principais fontes.

Nos processos infecciosos bacterianos localizados (fúngicos, parasitários, transplantes de órgãos, etc.), a expressão do gene CALC-I nos tecidos extra-tireoideos é limitada e com eles 
não ocorre um aumento significativo na síntese de PCT, por isso é um marcador confiável na sepse (Figura 2.) (MORALES, 2008; ANDRIOLO, 2004).

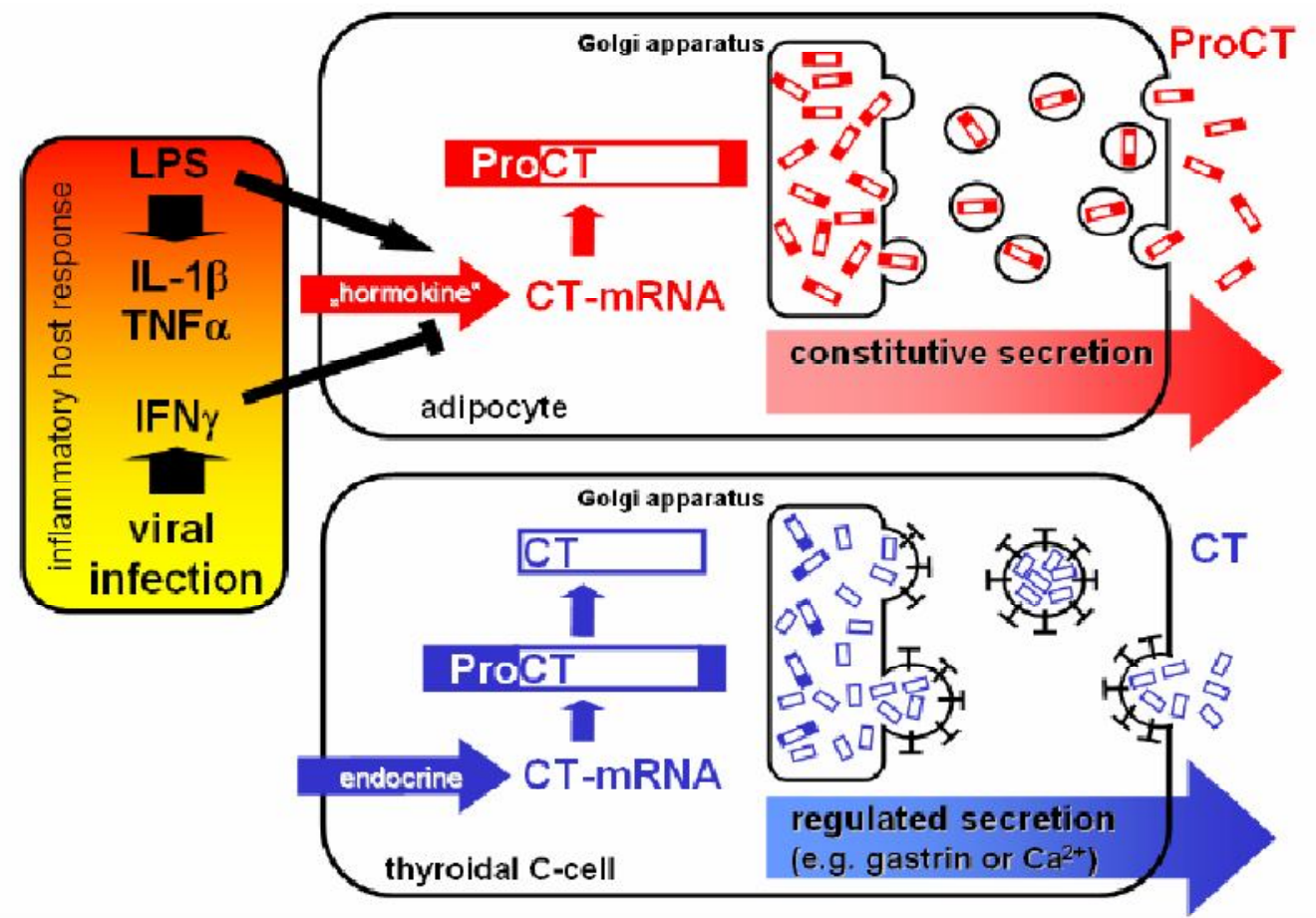

Figura 2: Diagrama esquemático da expressão do CALC-I em adipócitos como hormocinas em células C tireóideas como hormonios.

Fonte: DER WÜRDE, 2006. 
A análise quantitativa da expressão do CT-mRNA nos tecidos sépticos mostrou uma maior e significativa indução. Células parenquimatosas (incluindo fígado, pulmão, rim, e músculo) provêem a maior fonte do PCT circulante e a maior massa do tecido no sepse.

Em comparação com as clássicas citocinas, a expressão do Calcitonina-mRNA parece ser mais "up-regulated" uniformemente no sepse. A liberação inflamatória do PCT pode ser induzida diretamente via toxinas microbiais (eg. endotoxinas), via humoral indiretamente ou mediante resposta celular mediada ao hospedeiro (IL-1 $\beta$, TNF- $\alpha$, IL-6), (Figura. 3)

A indução pode ser atenuada por citocinas também lideradas durante infecção viral (eg. INF-

$\gamma)($ BRAHMS,2008)

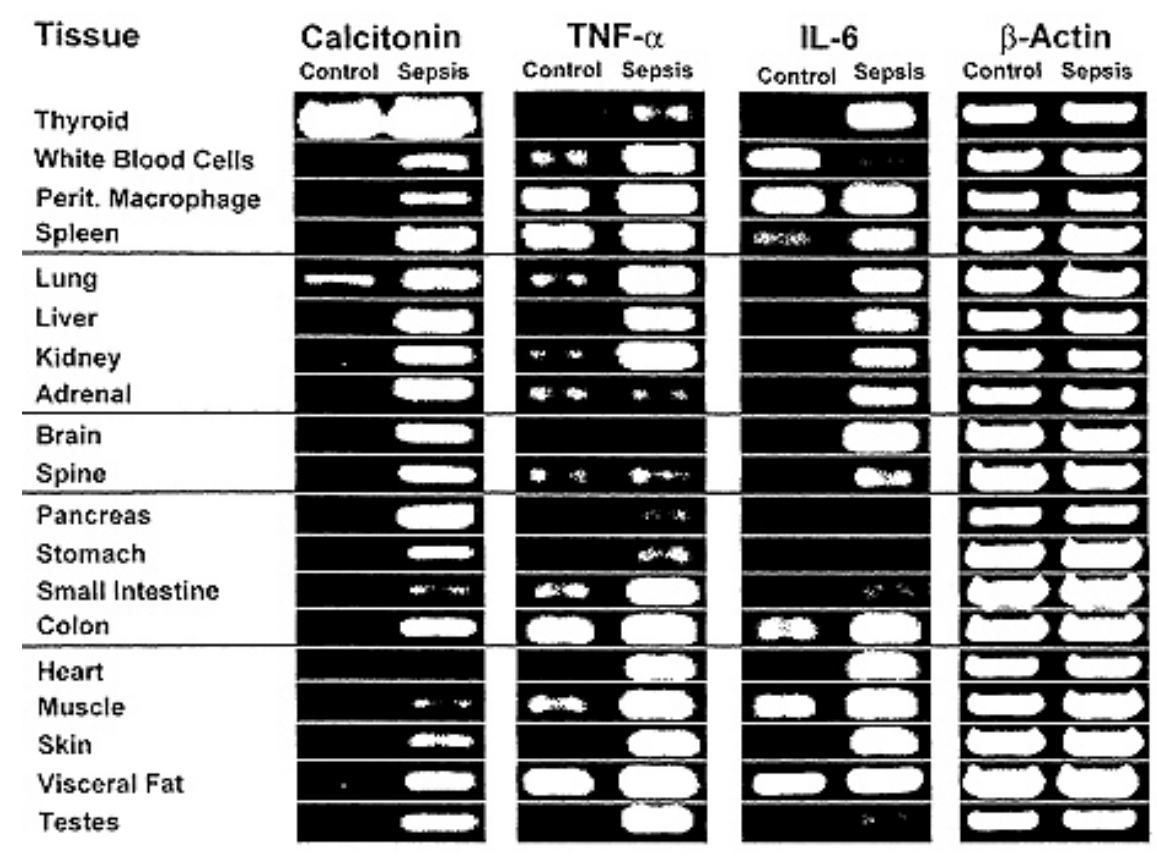

Figura 3: Produção das citocinas nos diferentes tecidos na sepse. 


\subsection{Níveis diagnósticos nas diferentes situações clínicas}

Em indivíduos saudáveis, níveis da PCT são menores a $0.1 \mathrm{ng} / \mathrm{ml}$, laboratórios também descrevem que medições com uma prova altamente sensível revelam como normais níveis inferiores de $0.05 \mathrm{ng} / \mathrm{ml}$ (97.5\% percentil). Em neonatos é diferente. Em paciente com sepse, níveis de PCT podem aumentar hasta 5000-10000 vezes com níveis de Calcitonina normais. Diferentemente da curta meia vida da Calcitonina (dez minutos), a meia vida da PCT é aproximadamente 24 horas. Depois de indução e presença duas horas antes de bacteremia, níveis aumentam rapidamente com uma meseta depois de 6-12hr, permanecendo elevadas até 48 horas com uma vida media de 20-24hs. .(REINHART 2006).

A concentração in vitro se reduz cerca de $12 \%$ a temperatura ambiente e $6 \%$ se mantida a $4^{\circ} \mathrm{C}$ em 24 horas. (BRAHMS, 2008)

A função fisiológica da PCT e seu lugar de produção não são completamente compreendidos. As Endotoxinas bacterianas são o maior estímulo para a indução da PCT, porém infecções por gram-positivos podem induzir também liberação da PCT. Durante infecções fúngicas severas, indução do PCT foi descrita em alguns pacientes, mais tem descrito alguns casos onde não foi observado incremento de PCT. (REINHART 2006; BRAHMS, 2008)

Também em grandes cirurgia, trauma severo, queimaduras podem induzir incremento do PCT. Níveis plasmáticos observados sob estas condições não são tão elevados como nos pacientes como sepse severa ou choque séptico.

Elevação no PCT é observada duas horas antes da bacteremia e diminui depois do tratamento sucedido indicando bom prognóstico, do mesmo modo níveis persistentemente elevados indicam falha ou re-infecção e mau prognóstico. 
Pacientes com níveis abaixo ou igual a $0.5 \mathrm{ng} / \mathrm{ml}$ dificilmente têm sepse ou choque séptico, em quanto que níveis acima de $2 \mathrm{ng} / \mathrm{ml}$ identificam pacientes com alto risco para estas condições.

Concentrações da PCT excedendo $10 \mathrm{ng} / \mathrm{ml}$ usualmente são vistas nos pacientes com disfunção orgânica distante do sitio da infecção. (MORALES,2008; SILVA, 2004).

Existem várias causas não infecciosas que podem resultar em alteraçoes nos níveis de PCT e não ser infecção:

\section{Aumento dos níveis da PCT}

Em grande cirurgia, e trauma severo onde PCT é liberada inespecificamente, monitoria diária pode ajudar a detecção das complicações sépticas prematuras.

Em neonatos, aumentos inespecíficos na PCT foram reportados, mais ainda medições conínuas foram úteis em sepse neonatal precoce. Neonatos de menos de 48 horas de vida têm elevação fisiológica.da PCT.

Em pacientes com choque cardiogênico prolongado ou severo e aqueles com anomalias de perfusão prolongada de órgãos observam-se incrementos nos níveis da PCT junto com outros sinais de inflamação sistêmica, como febre, leucocitose, e alterações nas citocinas, principalmente causadas por translocação da endotoxina depois da falha na perfusão gastrointestinal.

Neoplasias de pulmão (câncer de células pequenas) das células $\mathrm{C}$ medulares de tireóide podem aumentar ainda níveis da PCT. (LOBO, 2006) 


\section{Diminuicão dos níveis da PCT}

Níveis diminuídos nem sempre indicam ausência da infecção. Por exemplo, os falsos níveis diminuídos em curso inicial das infecções, infecções localizadas, endocardite infecciosa subaguda. (REINHART 2006; BRAHMS, 2008)

Apesar destas limitações, PCT pode discriminar entre causas infecciosas e não infecciosas de disfunção orgânica ou choque mais do que outro marcador. (REINHART 2006; ANDRIOLO, 2004).

Os clínicos que utilizam a PCT como marcador de infecção devem estar atentos a algumas limitações. Em um estudo de pacientes com mediastinite após cirurgia cardíaca, as concentrações de PCT foram próximas do normal e semelhante aos pacientes não-infectados (CHRIST, 2006).

Situações clínicas:

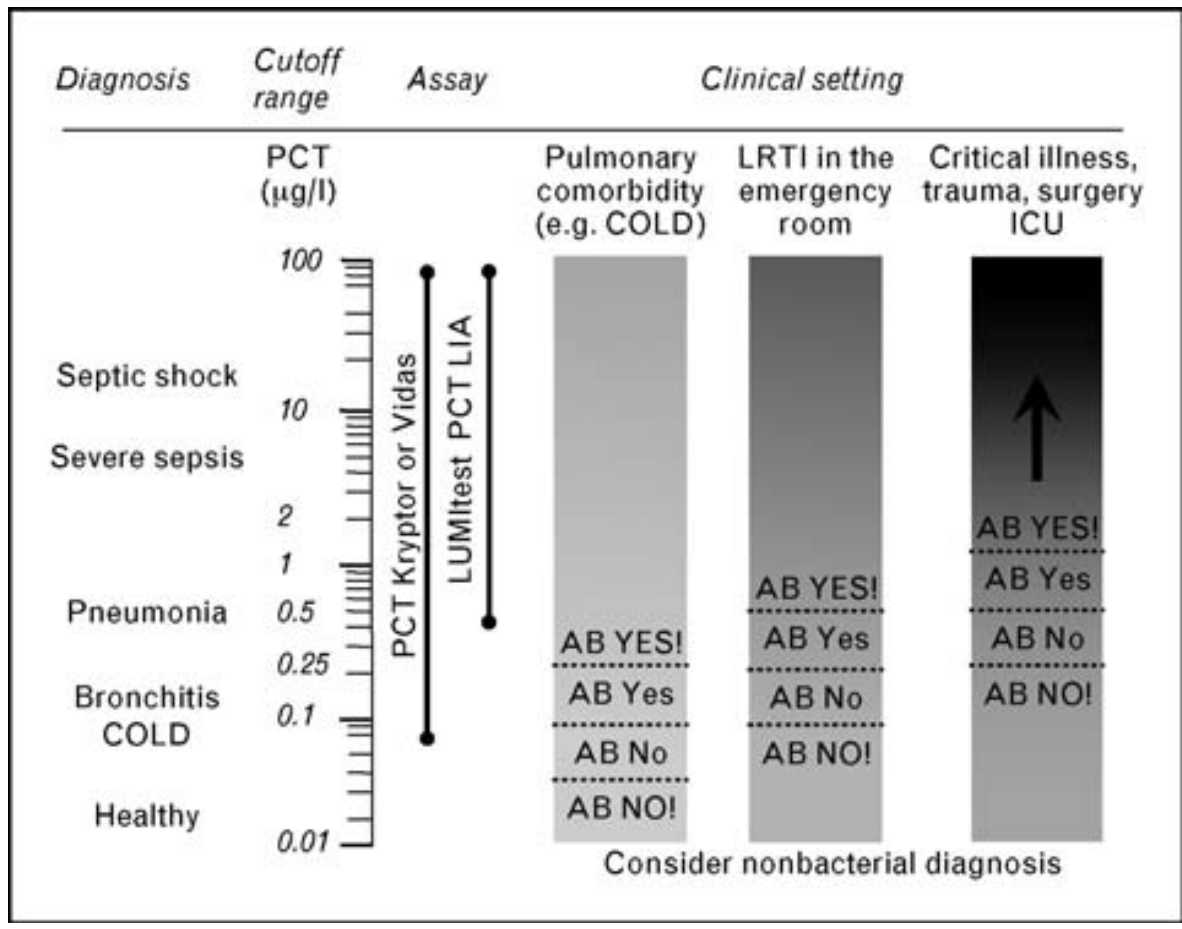

Figura 4: Adaptação dos valores da procalcitonina nas diferentes situações clinica Fonte: SCHUETZ. 2007. 


\begin{tabular}{|c|c|}
\hline$n g / u L$ PCT & Análise \\
\hline$<0,1$ & $\begin{array}{l}\text { Indica inexistência de infeç̧ão bacteriológica. Desin- } \\
\text { contiva-se com vocmência a utilização de antibióti- } \\
\text { cos, também perante um quadro de reserva pulmo- } \\
\text { nar diminuída em AECOPD }\end{array}$ \\
\hline 0,1 a $<0,25$ & $\begin{array}{l}\text { Infeç̧ão bacteriológica improvável. Desincentiva-se } \\
\text { a utilização de antibióticos }\end{array}$ \\
\hline $0,25 a<0,5$ & $\begin{array}{l}\text { Possibilidade de infeção bacteriológica. Recomen- } \\
\text { dação para iniciar a terapia antimicrobiana }\end{array}$ \\
\hline$>0,5$ & 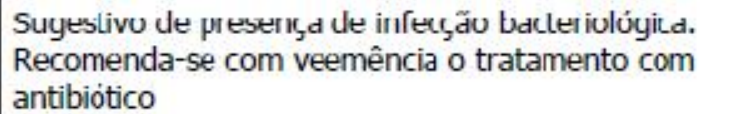 \\
\hline
\end{tabular}

Tabela 3: Diagnóstico diferencial das infecções do trato respiratório inferior Fonte: CHRIST-CRAIN, 2004

\subsection{Testes Laboratoriais}

Para medir a procalcitonina podem ser usadas varias provas, sendo estas quantitativas ou semiquantitativas.

Para medição da PCT quantitativa existe uma prova imuno-luminométrica PCT LIA (Brahms, Alemanha) é a equipe do luminómetro marca Berthold, modelo Lumat LB 9507 (Berthold Techonologies GmbH \& Co, Kg, Bad Wildbad, Alemanha). Usa como limite de detecção $0.01 \mathrm{ng} / \mathrm{ml}$.

A medição da PCT semiquantitativa pode ser realizada com a prova diagnóstica inmunocromatográfica PCT Q® (marca Brahms, Alemanha) aplicando seis gotas do soro através da uma pipeta no orifício da prova PCT $\mathrm{Q}^{\circledR}$ e incubando por 30 minutos. Posteriormente, pode ser determinado o setor de concentração da PCT semiquantitativa, segundo a intensidade da cor da banda (Tab. 3 y Fig. 5). 


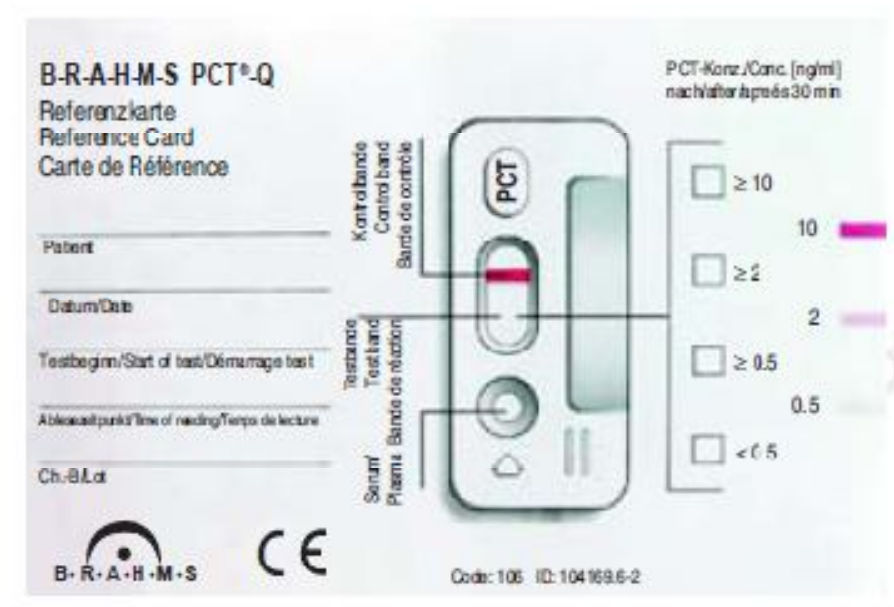

Figura 5. Mostra cartão do referência do nível da PCT com PCT®Q

Fonte: MORALES MUÑOZ, 2008.

A determinação da PCT Q ${ }^{\circledR}$ é uma prova fácil de realizar com resultados em menos de uma hora, podendo ter importância no diagnóstico da sepse em pacientes com SIRS de etiologia duvidosa na UTI. Uma possível desvantagem da PCT Q® é sua dependência do observador.

Gustavo e colaboradores (2008). fizeram um estudo correlacionando a determinação do PCT quantitativa e semiquantitativa no diagnóstico precoce do sepse na UTI. Estudaram 30 pacientes em dois grupos, um (16) com SRIS e outro (14) com sepse que ingressaram na UTI por um período de sete meses. Obteve amostras as 24, 48 e 72 horas, até no máximo de 6 amostras. Sepse bacteriana foi considerada com determinações de PCT $\geq 0.5 \mathrm{ng} / \mathrm{ml}$ (Tab. 4), concluindo que existe uma boa relação entre a determinação de PCT quantitativa e semiquantitativa, sendo essa maior quanto maior for o nível plasmático [r global= 0.62 y p < 0.001] (MORALES, 2008).

Devido a estabilidade in vivo, possuindo meia-vida de, aproximadamente, 20 a 24 horas, a coleta de sangue pode ser realizada seguindo-se os procedimentos habituais do laboratório 
clínico, sem necessidade de condições especiais. Caso a dosagem não seja realizada no dia da coleta, o soro deve ser mantido congelado. (ANDRIOLO, 2004)

\begin{tabular}{|c|c|}
\hline ng $/ m L$ PCT & Anallse \\
\hline \multirow[t]{2}{*}{$<0,5$} & $\begin{array}{l}\text { Possibilidade de infeç,ão bacteriológica local. } \\
\text { Infecçăo sıstémica (sépsis) }{ }^{[6]} \text { Improvável. } \\
\text { Reduzido risco de evolução para infecção sistémica } \\
\text { grave (sépsis grave) }\end{array}$ \\
\hline & $\begin{array}{l}\text { - Os niveis de PCT inferiores a } \\
0,5 \mathrm{ng} / \mathrm{mL} \text { não excluem a possibi- } \\
\text { lidade de infecção, já que as infec- } \\
\text { ções localizadas (sem sinais sisté- } \\
\text { micos) ooden estar associadas a } \\
\text { tais riveis baixos. } \\
\text { - Além disso, se a medição de PCT } \\
\text { for realizada muito precocemente } \\
\text { após desafio bacteriológico (geral- } \\
\text { mente < } 6 \text { horas), estes valores } \\
\text { podem continuar baixos. Neste ca- } \\
\text { so, o PCT deve ser reavaliado } 6 . . \\
24 \text { horas mais tarde. }{ }^{[4]}\end{array}$ \\
\hline \multirow[t]{2}{*}{$>0,5 \mathrm{e}<2$} & $\begin{array}{l}\text { Possibilidade de infecção sistémica (sépsis), mas sa- } \\
\text { be-se cue várias condiçốes também induzem PCT } \\
\text { (ver abaixo). }\end{array}$ \\
\hline & $\begin{array}{l}\text { Risco moderado de evolução para infeç̧ão sistémica } \\
\text { grave (sépsis grave) } \\
\text { U doente deve ser minucıosamente controlado clını- } \\
\text { camente e através de reavaliação da FCT dentro de } \\
6 . . .24 \text { horas. }\end{array}$ \\
\hline \multirow[t]{2}{*}{$>2 \mathrm{e}<10$} & $\begin{array}{l}\text { Possibilidade de infecção sstémica (sépsis), a menos } \\
\text { que se conheçam outras causas. }\end{array}$ \\
\hline & $\begin{array}{l}\text { Risco elevado de evoluçâo para infecçăo sistémica } \\
\text { grave (sépsis grave) }\end{array}$ \\
\hline \multirow[t]{2}{*}{$>10$} & $\begin{array}{l}\text { Importante resposta infamatória sistémica, quase } \\
\text { exclusivamente devido a sépsis bacterológica grave } \\
\text { ou choque séptico }\end{array}$ \\
\hline & $\begin{array}{l}\text { Elevada probabilidade de sépsis grave ou choque } \\
\text { séptico.6] }\end{array}$ \\
\hline
\end{tabular}

Tabela 4. Interpretação da PCT elevada e suas implicações diagnósticas e terapêuticas Fonte: MORALES MUÑOZ, 2008. 


\subsubsection{Provas quantitativas}

\section{PCT LIA:}

PCT LIA é um ensaio imuno-luminométrico (ILMA) usado para determinar a concentração de PCT no soro e plasma humanos. Para isso são adicionados em excesso dois anticorpos monoclonais antígeno-específicos que ligam a PCT (o antígeno) em dois locais diferentes de ligação: nos segmentos de calcitonina e nos de catacalcina. Um destes anticorpos é marcado com luminescência (marcador) e o outro é fixado à superfície interior do tubo (sistema de tubo revestido).

Durante a fase de incubação, ambos anticorpos reagem com as moléculas de procalcitonina na amostra, levando a formação dos assim chamados "complexos sanduíche". Como resultado, o anticorpo marcado com luminescência liga-se à superfície interior do tubo. Após o final da reação, o excesso de marcador remanescente é completamente removido e eliminado do tubo mediante lavagem.

Depois, a quantidade residual de marcador na superfície interior do tubo de teste é quantificada através da medição do sinal luminescente, utilizando-se para o efeito um luminímetro apropriado e os reagentes do kit básico $\mathbf{B} \cdot \mathbf{R} \cdot \mathbf{A} \cdot \mathbf{H} \cdot \mathbf{M} \cdot \mathbf{S}$ Basiskit LIA®. A intensidade do sinal luminescente (RLU) é diretamente proporcional à concentração de PCT na amostra. Após se traçar uma curva-padrão usando-se padrões com concentrações já conhecidas de antígeno (calibradas em relação à procalcitonina sintética e intacta humana), as concentrações desconhecidas de PCT nos soros ou plasmas dos pacientes podem então ser quantificadas por meio de uma comparação dos valores do teste com a curva.

Alternativamente, usando-se calibradores em vez de padrões, as concentrações de PCT desconhecidas nas amostras de soro ou plasma de pacientes podem ser quantificadas comparando-se os valores de teste com uma curva padrão elaborada pelo laboratório. 
As concentrações de PCT no soro ou plasma de indivíduos saudáveis medidas com este ensaio são $<0,3 \mathrm{ng} / \mathrm{ml}$, portanto abaixo do limite de detecção do ensaio. (BRAHMS, 2008)

Diagnóstico de SIRS, Sepse, Sepse Severa e Choque Séptico foram categorizados de acordo com os critérios da conferência de consenso do American College of Chest Physicians/Society of Critical Care Medicine (BONE,1992).

\section{PCT Sensitive KRYPTOR:}

O princípio de medição dos $\mathrm{B} \cdot \mathrm{R} \cdot \mathrm{A} \cdot \mathrm{H} \cdot \mathrm{M} \cdot \mathrm{S}$ KRYPTOR/KRYPTOR compact baseia-se na tecnologia TRACE (Time-Resolved Amplified Cryptate Emission), que mede o sinal que é emitido a partir de um imunocomplexo com atraso. A base da tecnologia TRACE é a transferência de energia não radioativa de um doador (uma estrutura tipo gaiola com um íon de európio ao centro [criptato]) para um receptor, que faz parte de uma proteína quimicamente modificada provinda de uma alga coletora de luz (XL $665)$.

As concentrações de PCT no soro ou plasma de indivíduos saudáveis são avaliadas com este ensaio como 0,064 ng/mL (percenti195\%).

SIRS, Sepse, Sepse grave e choque séptico foram classificados de acordo com critérios da conferência de consenso da ACCP/SCCM (BONE,1992).

A PCT sensitive KRYPTOR é recomendada para detecção de infecções bacterianas do

Sistema Respiratório por sua melhor sensibilidade, não recomendando-se PCT LIA,

PCT LIAISON ou PCT-Q (BRAHMS,2008).

\section{LIAISON $^{\circledR} B \cdot \mathbf{R} \cdot \mathbf{A} \cdot \mathbf{H} \cdot \mathrm{M} \cdot \mathrm{S}$ PCT}

Ensaio in vitro para a determinação quantitativa de pró-calcitonina (PCT) no soro 
Humano. A amostra pode ser também plasma heparinizado, citratado ou com EDTA.

O teste é realizado no Analisador LIAISON®.

Em indivíduos com metabolismo normal, a PCT é decomposta por

Proteólise e normalmente a PCT é eliminada em níveis indetectáveis $(<0,1 \mathrm{ng} / \mathrm{ml})$

pelos indivíduos saudáveis. Nas infecções graves por bactérias, fungos e parasitos,

assim como na sépse, o título sérico da PCT pode ultrapassar os 500 ng/ml.

As células sanguíneas mononucleares são, entre outras, atualmente consideradas como

local da síntese da pró-calcitonina em condições de resposta inflamatória sistêmica. A

prova é um ensaio imuno-luminométrico de dois locais (princípio sanduíche). São

usados dois anticorpos monoclonais diferentes altamente específicos para revestimento da fase sólida (partículas magnéticas) e para o traçador.

\begin{tabular}{|c|c|}
\hline Limites de Referência & $\mathrm{PCT}(\mathrm{ng} / \mathrm{ml})$ \\
\hline Sujeitos normais ( 95 dodores de sangue aparentenente saucóveis) $(7)$ & $<0.5$ \\
\hline Processos inflanatorios crónicos e doenças autcimunes (B) & $<0.5$ \\
\hline Infecçōes virais & $<0.5$ \\
\hline Infeccōes bacterianas localizadas ligeiras a mocerodas (1 1) & $<0.5$ \\
\hline SIRS, trauma multiplo, queimaduras (I 2) & $0.5-2.0$ \\
\hline $\begin{array}{l}\text { Várics infeç̧ōes bacterianas, sépsis, insuficiência múltipla } \\
\text { de óigãos }(5,10)\end{array}$ & $\begin{array}{l}>2.0 \text { (muitas } \\
\text { vezes } 10.100 \text { ) }\end{array}$ \\
\hline
\end{tabular}

Tabela 5: Interpreção dos Resultados da prova LIAISON ${ }^{\circledR} \mathrm{B} \cdot \mathrm{R} \cdot \mathrm{A} \cdot \mathrm{H} \cdot \mathrm{M} \cdot \mathrm{S}$ PCT Fonte: BRAHMS, 2008. 


\subsubsection{SEMI-QUANTITATIVAS:}

\section{PCT Q:}

É um teste imunocromatográfico destinado à medição semi-quantitativa da PCT (procalcitonina), para o diagnóstico e controle do tratamento de infecções bacterianas severas e sepse. $\mathrm{O} B \cdot \mathrm{R} \cdot \mathrm{A} \cdot \mathrm{H} \cdot \mathrm{M} \cdot \mathrm{S}$ PCT-Q é um sistema de teste com um período de incubação de apenas 30 minutos, o qual não depende de equipamentos e não requer calibração.

O teste utiliza um anticorpo anti-catacalcina monoclonal de rato, conjugado com ouro coloidal (marcador) e um anticorpo anti-calcitonina policlonal de ovelha (fase sólida). Após a aplicação da amostra do paciente (soro ou plasma) na fita de teste, o marcador liga-se à PCT da amostra, levando à formação de um complexo antígeno-anticorpo marcado. Esse complexo move-se, por força capilar, através do sistema de teste e, nesse processo, passa pela área contendo a banda de teste. Aqui, o complexo antígenoanticorpo marcado liga-se aos anti-corpos anti-calcitonina fixados e forma um assim chamado "complexo de sanduíche".

Numa concentração de $\mathrm{PCT} \geq 0,5 \mathrm{ng} / \mathrm{ml}$ esse complexo de sanduíche pode ser visualizado como uma banda de cor avermelhada. A intensidade da coloração da banda é diretamente proporcional à concentração de PCT na amostra e, com a ajuda de um cartão de referência, é ordenada nas seguintes amplitudes de concentração de PCT: $<0.5 \mathrm{ng} / \mathrm{ml} ; \geq 0.5 \mathrm{ng} / \mathrm{ml} ; \geq 2 \mathrm{ng} / \mathrm{ml} ; \geq 10 \mathrm{ng} / \mathrm{ml}$ (Fig. 6).

O marcador livre (não ligado) difunde-se na zona da banda de controlo, onde se fixa e produz uma banda de controle de coloração vermelha intensa. Essa banda de controle permite examinar a capacidade funcional do sistema de teste. PCT-Q tem 90-92\% de 
sensibilidade e 92\%-98\% de especificidade comparada com PCT-LIA

(BRAHMS, 2008).

As concentrações de PCT no soro ou plasma de indivíduos saudáveis medidas com este ensaio são $<0,5 \mathrm{ng} / \mathrm{ml}$, portanto abaixo do limite de detecção do ensaio.

(BRAHMS, 2008)

Diagnóstico de SIRS, Sepse, Sepse Severa e Choque Séptico foram categorizados de acordo com os critérios da conferência de consenso do ACCP/SCCM (BONE,1992).
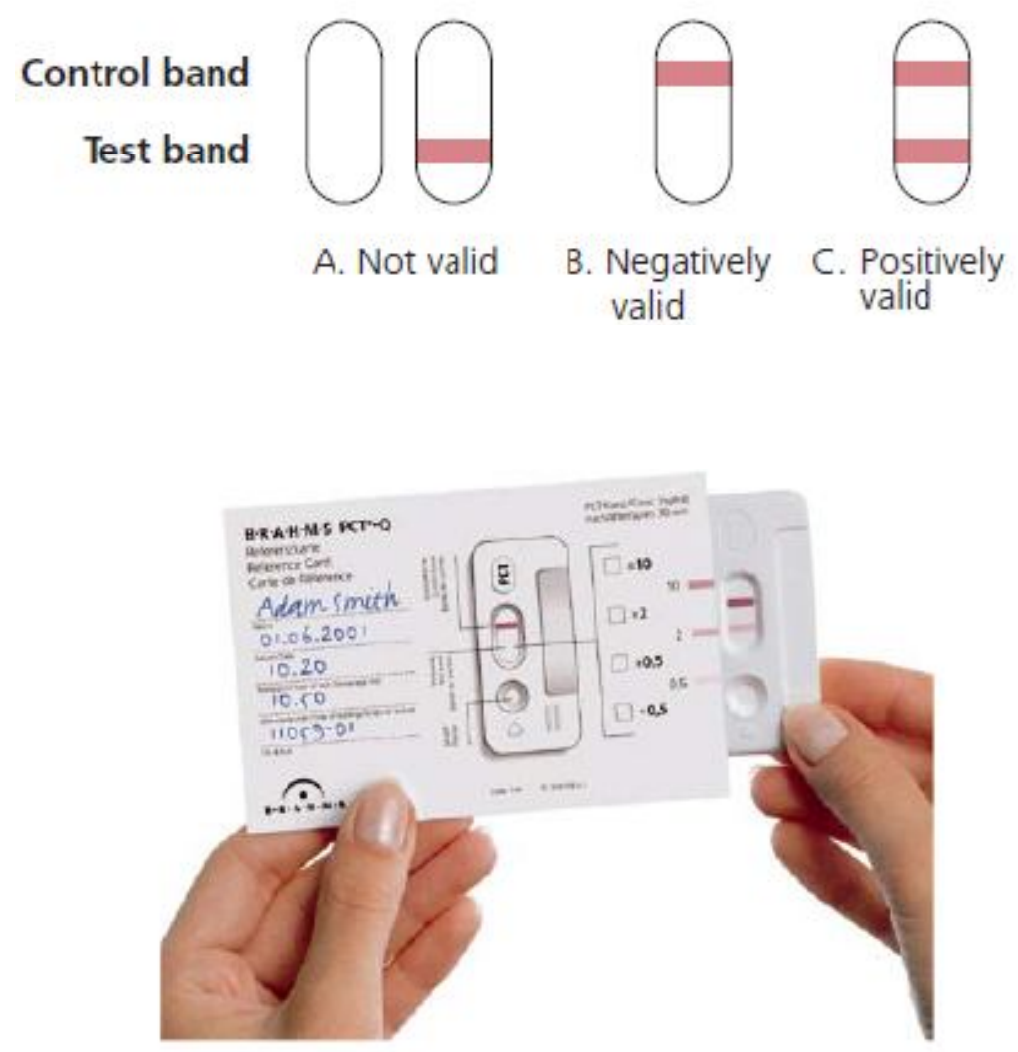

Figura 6: Interpretação dos Resultados da prova PCT $Q^{\circledR} \mathbf{B} \cdot \mathbf{R} \cdot \mathbf{A} \cdot \mathbf{H} \cdot \mathbf{M} \cdot \mathbf{S}$ Fonte:BRAHMS, 2008 


\subsection{Estudos e Situações clínicas}

Muitos estudos confirmam a PCT como marcador para infecções severas e sepse.

De acordo com SCHUETZ e colaboradores (2007) baseados na evidência proveniente de quatro estudos de intervenção randomizados com mais do 1250 pacientes (Pro.RESP, ProCAP, ProCOLD, PARTI), procalcitonina incrementou seu poder de decisão clínico e antibiótico sem nenhuma repercussão nos desfechos ou efeitos adversos relacionados com o uso de antibióticos.

Baseados na capacidade de discriminação da procalcitonina no fluxograma, deve considerarse determinação freqüente da procalcitonina para diagnostico no paciente febril criticamente doente.

Assim, na admissão deve ser feita a avaliação clinica y laboratorial, medindo procalcitonina. O uso de antibióticos deve ser baseado no cutt-off dos níveis da PCT, porém deve ser observado o fluxograma. Nos doentes com comprometimento da vida iniciar terapia antibiótica de amplo espectro, e as medições da PCT devem ser feitas após 6-24hs. Níveis baixos no seguimento indicam doença não infecciosa; com terapia antibiótica em andamento os níveis da PCT devem são avaliados apos 3, 5 e 7 dias, considerando suspensão baseados nos níveis de PCT e evolução clínica Nas UTIs os níveis da PCT em doentes críticos com SIRS, estão moderadamente elevados ainda na ausência de infecção, por isto podem ser usados níveis superiores da PCT que na emergência.

Nos doentes com níveis da PCT muito elevados (>10 $\mu \mathrm{g} / \mathrm{l})$, antibióticos são suspensos com níveis 80 e 90\% mais baixos ao nível inicial. (Fig. 7) (SCHUETZ, 2007) 


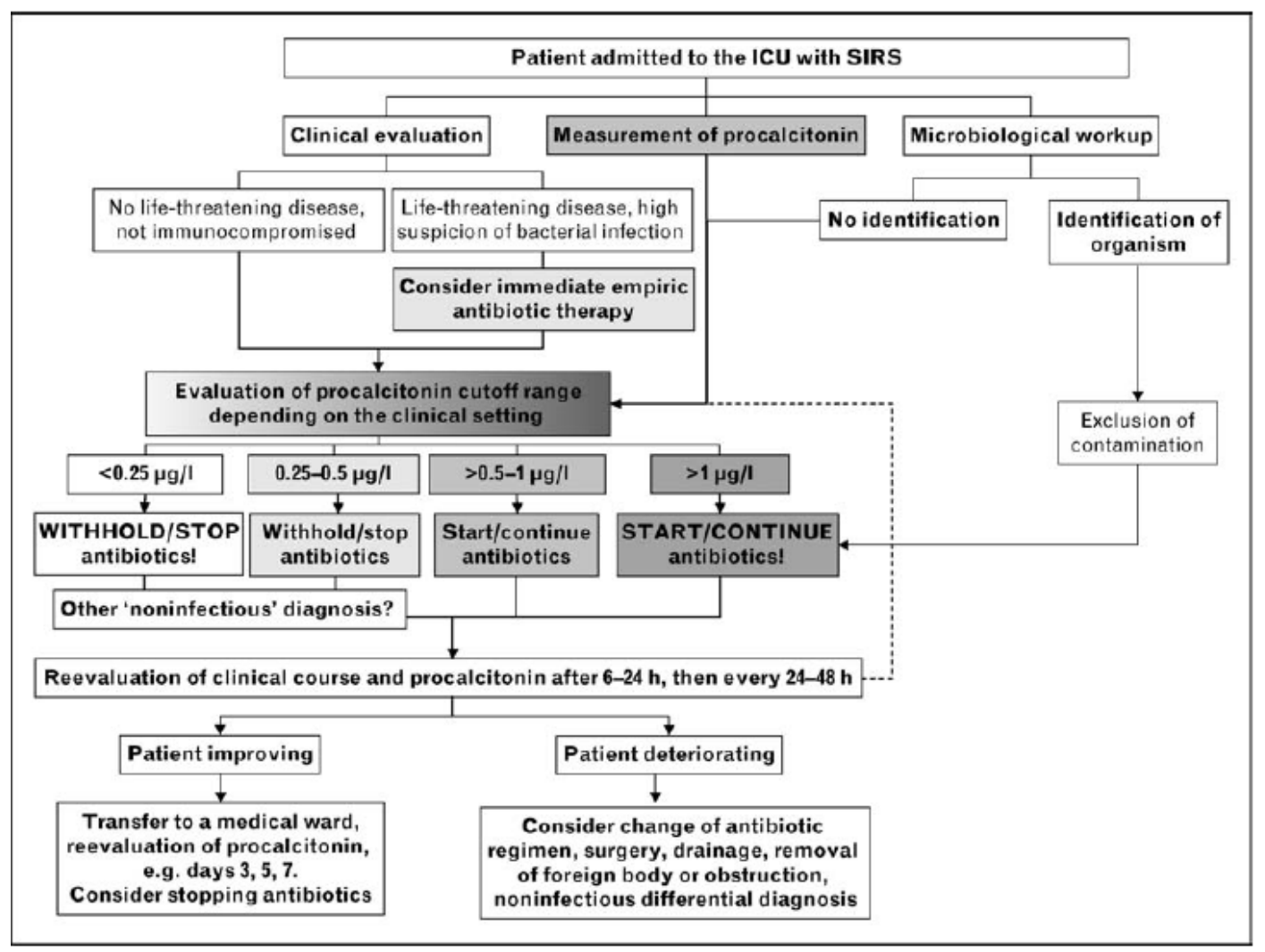

Figura 7 Fluxograma com PCT guiando o tratamento antibiótico no pacientes criticamente doentes.

Fonte: SCHUETZ. 2007..

No estudo Pro.Resp (BRIEL,2005), PCT usada como guia, reduziu a formulação antibiótica em 243 pacientes com LRTI em 50\%. (Fig.7.)

O estudo ProCAP, (CHRIST-CRAIN, 2006) logrou menor duração das terapias antibióticas, reduzindo em $65 \%$ tempo de duração, trocando do 12,9 a 5,8 dias, com iguais desfechos incluindo todos os graus da severidade da Pneumonia Adquirida na Comunidade (PAC).

Estudo ProCOLD (STOLZ, 2007) demonstrou boa segurança a longo prazo, tendo igual proporção de re-admissão em 6 meses com 200 exacerbações agudas da Doença Pulmonar Obstrutiva Crônica (DPOC) , com diminuição do uso dos antibióticos guiado por níveis da PCT, usados em 40\% dos pacientes comparado com grupo controle (72\%). 


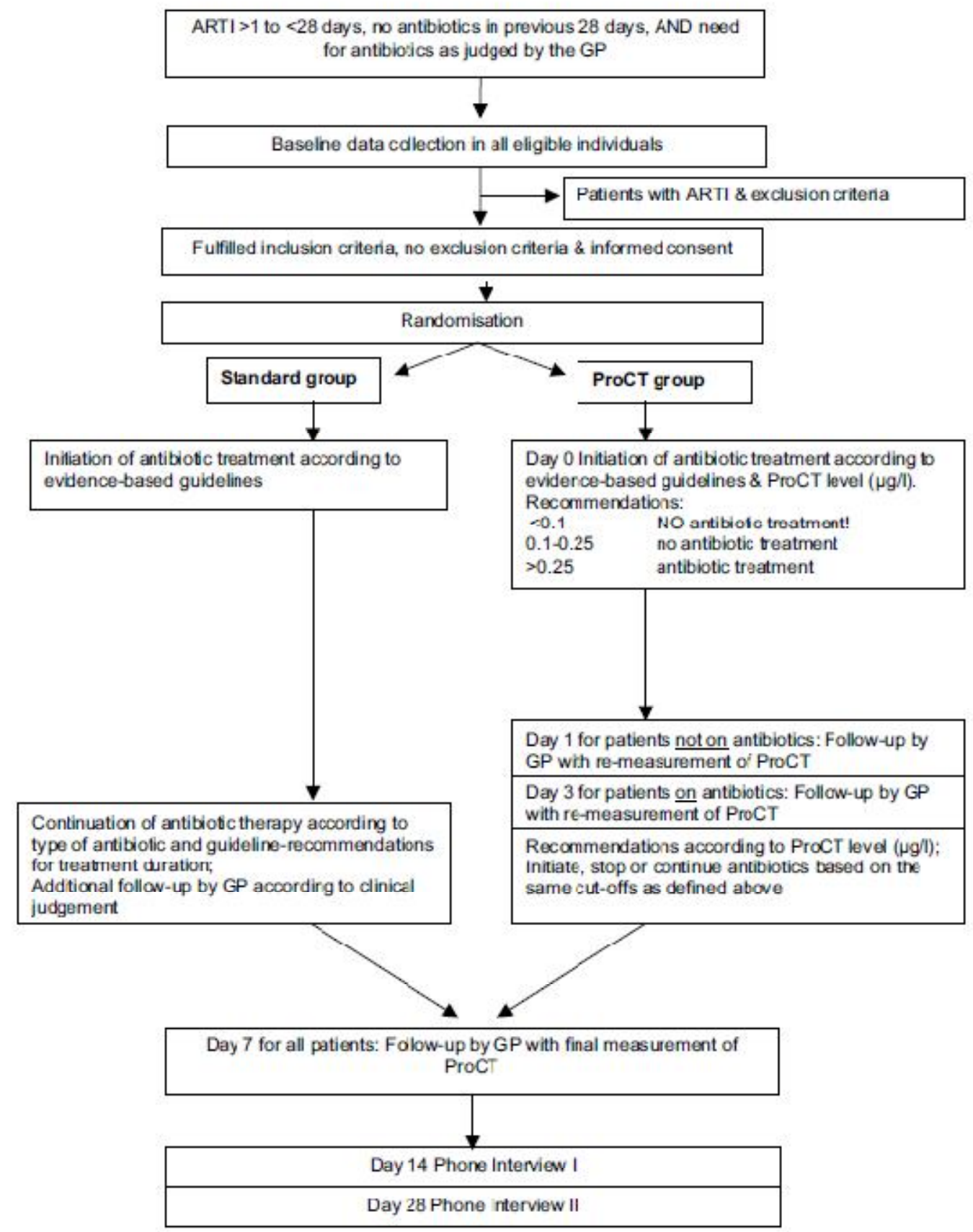

Figura 7: Resumo do desenho do estudo.

Fonte: BRIEL, 2005. 
Procalcitonina pode ser usado como complemento no diagnóstico e prognóstico da Pneumonia associada a ventilação (PAV), infecção mais freqüente nos pacientes com ventilação mecânica (LUYT, 2005)

Na Endocardite PCT e superior que PCR, sendo o único preditor da endocardite infecciosa na admissão, mas na endocardite o paciente deve ter hemoculturas positivas, e demais sinais clínicos.(MÜLLER, 2004, SCHUETZ, 2007)

Meisner e colaboradores (1999) estudaram a relação dos níveis da PCT nos pacientes com diferente severidade da SDOM com inflamação sistêmica comparados com níveis da PCR. Concluiram que os níveis da PCT estão associados com a severidade do SDMO, avaliado com escala SOFA (Sepsis-related Organ Failure Assessment).

Diante do exposto, os clínicos não devem menosprezar a semiótica, os dados clínicos e analisar com cuidado as limitações deste s exames. 


\section{7 - CONCLUSÃO}

Os biomarcadores são ferramentas úteis que em algum momento foram uma utopia, mais hoje são uma realidade factível para muitos profissionais da saúde, e também estão ganhando terreno em nossa prática clínica até fazer parte de nosso conjunto de critérios na hora de tomar uma decisão clínica no contexto da patologia infecciosa dos pacientes.

Graças a essa observação detalhada dos fenômenos fisiopatológicos ocorridos nos organismos durante a instalação da infecção, foram esclarecidos aspectos que podem ajudar a clarear nosso obscuro caminho na hora de tratar a infecção e ter melhores resultados. Por esse desconhecimento mesmo, gastamos mais recursos, usamos mais antibiótico desnecessariamente, prolongamos hospitalizações, levando nosso sistema de saúde algumas vezes ao colapso.

Os Biomarcadores não são mais que isso, marcadores biológicos que nosso corpo produz em resposta a uma agressão, e são hoje alvo de investigação da comunidade científica cada dia mais preocupada com aumento da resistência bacteriana, microorganismos mais agressivos, retardando nossa capacidade de ação, levando a piores desfechos.

Hoje temos mais pacientes, com patologias mais críticas, em nossas UTIs que podem mantêlos com melhor suporte, prolongando a vida. Nossos profissionais trabalham com pacientes inmunossuprimidos, agredidos, invadidos pela assistência terapêutica sem capacidade de resposta, sendo nestes onde os patógenos desenvolvem mais e são mais difíceis diagnosticar e tratar. Os biomarcadores então podem ser úteis melhorando os critério na hora de tomar uma decisão, racionalizando o uso dos antibióticos, diminuindo custos e o tempo de internação, o prognóstico e conseqüentemente a melhorando qualidade de vida. Pode ser útil ainda no seguimento ambulatorial de pacientes com infecções. 
A procalcitonina é um dos tantos biomarcadores e vem sendo usado com êxito no monitoramento de pacientes criticamente doentes pelas infecções e também no acompanhamento deles fora do ambiente hospitalar, especialmente aqueles com doenças respiratorias. Esta pode ser utilizada com confiança na avaliação da sepse, no seguimento do tratamento antibiótico para controle de um foco infeccioso. Apresenta excelente correlação como outros marcadores inflamatórios (e.g. citocinas).

A avaliação da infecção sistêmica deve ser feita, com ajuda de adequada avaliação clinica, prestando atenção as sinais clínicas e aos dados laboratoriais para tomar uma adequada decisão.

Em casos graves que o diagnóstico de sepse é difícil e a decisão de iniciar ou retardar a terapia anti-infecciosa possui implicações importantes, níveis séricos de PCT podem ser utilizados, também para avaliar a gravidade de um quadro séptico.

PCT não é o único biomarcador que temos, mas é o mais sensível e específico que reforçará a avaliação clinica e laboratorial usual.

Sendo as Doenças Tropicais que as vezes culminam no SRIS, devem-se investigar biomarcadores para melhorar o prognóstico destas doenças, que cada dia deixam de ser um problema dos países não desenvolvidos e são parte do panorama mundial.

É importante investir no conhecimento sobre biomarcadores para esclarecer, evidenciar e validar sua importância no controle das infecções. 


\section{8- REFERÊNCIAS BIBLIOGRÁFICAS}

ALBERTI C. et al. Epidemiology of sepsis and infection in ICU patients from an international multicentre cohort study. Intensive Care Med. v. 28. 2002. 108-121

ANDERSON, R. National Vital Statistics Reports [serial online]. 2002. National Vital Statistics Report,. v. 50, n. 16. 2002. 1-88. Disponível em:

http: //www.cdc.gov/nchs/data/nvsr/nvsr50/nvsr50_16.pdf. Accesado em: 21/10/08.

ANDRIOLO, Adagmar. et. al. Pró-calcitonina e proteína $\mathrm{C}$ reativa em processos infecciosos graves. J Bras Patol Med Lab. v. 40, n. 3. 2004. 169-174

ANGUS, D. et. al. Epidemiology of severe sepsis in the United States: analysis of incidence, outcome, and associated cost of care. Crit Care Med v. 29, n. 7. 2001. 1303-1310.

BECKER KL, NYLEN ES, WHITE JC. Procalcitonin and the calcitonin gene family of peptides in inflammation, infection, and sepsis: a journey from calcitonin back to its precursors. J Clin Endocrinol Metab v.89 2004. 1512-1525.

BONE, RC et al. Definitions for sepsis and organ failure and guidelines for the use of innovative therapies in sepsis. The ACCP/SCCM Consensus Conference Committee. American College of Chest Physicians/Society of Critical Care Medicine. Chest. v. 101.n.6,1992.1644-1655.

Disponível em: http: // chestjournal.org/cgi/content/abstract/101/

BRAHMS AKTIENGESELLSCHAFT LABORATORY. Acesso à informação das provas do PCT. Disponivel em:

http://www.brahms.de/Default.aspx?tabindex=0\&tabid=148\&search=LUMITEST\&art=All. Acceso em 22/10/08

Acceso animado a PCT-Q

http://www.procalcitonin.com/products/pctqflash.htm

BRIEL, Matthias. et al. Procalcitonin-guided antibiotic use versus a standard approach for acute respiratory tract infections in primary care: study protocol for a randomised controlled trial and baseline characteristics of participating general practitioners [ISRCTN73182671] BMC Family Practice.v. 6. 2005, 1-8

Disponivel em: http://www.biomedcentral.com/1471-2296/6/34. Acceso em 10/10/08

. Procalcitonin-guided antibiotic use versus a standard approach for acute respiratory tract infections in primary care: study protocol for a randomised controlled trial and baseline characteristics of participating general practitioners [ISRCTN73182671].Arch. Intern. Med. v. 168, n. 18. 2008. 
CHRIST-CRAIN M. et. al. Procalcitonin guided reatment on antibiotic use and outcome in lower respiratory tract infections: cluster-randomised, single-blinded intervention trial. Lancet. v. 363. 2004. 600-607.

Procalcitonin guidance of antibiotic therapy in community-acquired pneumonia: a randomized trial. Am J Respir Crit Care Med v. 174. 2006; 84-93.

DELLINGER, R. Phillip. et. al. Surviving Sepsis Campaign: International guidelines for management of severe sepsis and septic shock: 2008. Int. Care Med. DOI 10.1007/s00134007-0934-2.

DER WÜRDE Erlangug. Hormokines: A novel concept of plasticity in Neuro-EndoImmunology. Apresentação de trabalhos, dissertações es teses: Universidade Basel von Dalma Sebök aus Sempach (LU): 2006.

LOBO Suzana, et al. Markers and Mediators of Inflamatory Response in Infection and SepsisIndicadores e Mediadores de Resposta Inflamatória na Infecção e Sepse. Revista Brasileira de Terapia Intensiva. v. 19, n. 2. 2007. 211-215.

LUYT CE. et. al. Procalcitonin kinetics as a prognostic marker of ventilator-associated pneumonia. Am J Respir Crit Care Med. v.171 n. 2005. 48-53

MEISNER, Michael. et. al. Comparison of procalcitonin (PCT) and C-reactive protein (CRP) plasma concentrations at different SOFA scores during the course of sepsis and MODS. Crit Care. v. 3. 1999. 45-50

MORALES, Gustavo et al. Correlación de la pruebas diagnosticas de la procalcitonina cuantitativa versus semicuantitativa. Rev. Asoc. Mex. Med. Crit. y Ter. Int. v. 22, n. 3, 2008. 143-148

MÜLLER C. et. al. Procalcitonin and the early diagnosis of infective endocarditis. Circulation. v. 109. 2004.1707-1710.

B-type natriuretic peptide for risk stratification in community-acquired pneumonia. $\mathbf{J}$ Intern Med. v. 258. 2005. 391-393.

NYLEN ES, Whang KT, Snider RH Jr, et al. Mortality is increased by procalcitonin and decreased by an antiserum reactive to procalcitonin in experimentalsepsis. Crit Care Med v. 26. 1998;1001-1006.

REINHART Konrad et. al. Markers for Sepsis Diagnosis:What is Useful?. Crit Care Clin. v. 22. 2006. 503-519

SCHUETZ Philipp et.al. Biomarkers to improve diagnostic and prognostic accuracy in systemic infections. Curr. Opin. Crit. Care. v. 13, 2007. 578-585. 
Procalcitonin guided antibiotic therapy and hospitalization in

patients with lower respiratory tract infections: a prospective, multicenter, randomized controlled trial BMC Health Services Research. v. 7.2007.2-9. Disponível em:

http://www.biomedcentral.com/1472-6963/7/102 Acceso em: Agosto de 2008

SILVA,E. et al. CONSENSO BRASILEIRO DE SEPSE. [2003?] Disponível em:

http: // www.laadti.unifesp.br/sepse.html. Acceso em: 21/10/08.

Brazilian Sepsis Epidemiological Study (BASES study). Crit. Care.

v. 8, n. 4. 2004. R252-R260. Disponível em: http://ccforum.com/content/8/4/R251

STOLZ, D. et. al. Antibiotic treatment of exacerbations of COPD: a randomized, controlled trial comparing procalcitonin guidance with standard therapy. Chest. v. 131, 2007; 9-19.

UZZAN B. et al. Procalcitonin as a diagnostic test for sepsis in critically ill adults and after surgery or trauma: A systematic review and meta-analysis. Crit Care. v. 34, n. 7. 2006. 19962003.

Site de interesse:

ClinicalTrial.gov. Dísponivel em:

http://clinicaltrials.gov/ct/search;jsessionid=A8117FBDE264EA87CAFB1D752C4D4E90?t erm=procalcitonin\&s 